Archived version from NCDOCKS Institutional Repository http://libres.uncg.edu/ir/asu/

\title{
Appalachlyan
}

B O O N , N O R T H C A R O L I N A

\section{Bridging Disciplines with the Riparian Area Management Project}

\author{
Authors \\ Kristan M. Cockerill and Jonathan H. Titus
}

\begin{abstract}
$\underline{\text { Abstract }}$
Faculty at Columbia University's Earth Semester created the interdisciplinary Riparian Area Management Project to help students integrate information and skills from life sciences, geosciences, social sciences, and humanities focused coursework. Structured as a "consulting" contract, students were required to make a policy recommendation utilizing diverse data and struggling with the complexity inherent in a real situation with no single "right" answer. While Earth Semester was a unique program, the Riparian Project is adaptable to any educational system.
\end{abstract}

Cockerill, K. and J. H. Titus. (2004). Bridging Disciplines with the Riparian Area Management Project. Applied Environmental Education and Communication 3(3):163-170. (Jul 2004) Published by Taylor \& Francis (ISSN: 1533-0389). DOI: 10.1080/15330150490485958 
Cockerill, K. and J. H. Titus. (2004). Bridging Disciplines with the Riparian Area Management Project. Applied Environmental Education and Communication 3(3):163-170. (Jul 2004) Published by Taylor \& Francis (ISSN: 1533-0389). DOI: 10.1080/15330150490485958

\title{
Bridging Disciplines with the Riparian Area Management Project
}

Kristan M. Cockerill and Jonathan H. Titus

\begin{abstract}
Faculty at Columbia University's Earth Semester created the interdisciplinary Riparian Area Management Project to help students integrate information and skills from life sciences, geosciences, social sciences, and humanities focused coursework. Structured as a "consulting" contract, students were required to make a policy recommendation utilizing diverse data and struggling with the complexity inherent in a real situation with no single "right" answer. While Earth Semester was a unique program, the Riparian Project is adaptable to any educational system.
\end{abstract}

\footnotetext{
ARTICLE

A steady stream of articles, reports, and web pages continues to provide information about interdisciplinary environmental education. There are numerous examples of environmental studies programs that require students to take courses from a diverse array of specialties (cf. Drury University or Colorado College). One common-sense reason for encouraging interdisciplinary work is to enable students to address environmental concerns more effectively, concerns which are almost always interdisciplinary, when they enter the workplace. Into this educational flow the authors add a simulation project designed to help students appreciate the
} 
difficulties in interdisciplinary work, as well as the potential benefits that such work brings to policy-making. The Riparian Area Management Project (Riparian Project) developed for Columbia University's Earth Semester provided a bridge for students to cross disciplines and apply diverse skills and knowledge to a policy concern. This project accepted the claim that "Interdisciplinary cooperation is a more effective way to conduct policy studies that will minimize environmental and health risks to the public" (Susskind, Jain, \& Martyniuk, 2001, p. 39) and attempted to provide students with a realistic experience in policy research. Simulations like this allow students to apply skills that they will likely use in their future careers and to learn without risking pay or reputation in the "real world" (Galea, 2001).

The interdisciplinary aspect of the Riparian Project is especially salient, as professional associations pay increasing attention to the need for higher education to prepare students for the interconnectedness among professions - especially the connections between the "hard" sciences and other disciplines, such as policy. For example, annual meetings of the Geological Society of America typically include numerous presentations devoted to the connections among earth science, social science, and the humanities (cf. Rowe \& Bjornerud, 1999; Colodner \& Cockerill, 2000; Whitman, 1996). The Ecological Society of America has similar efforts. This attention to bridging disciplines is also finding its way into textbooks. The Principles of Conservation Biology (1997) edited by Gary Meffe and Ronald Carroll, is one example of a science-based textbook that grants significant attention to the historical, cultural, economic, and policy connections to conservation biology. Even with this strong information current, however, educators are still learning how best to teach within a nontraditional milieu and are still refining what readings, lectures, and projects might best prepare students for what they will likely face if they pursue careers related to environmental policy.

As an earth scientist who served as a Congressional Fellow, Eileen McLellan (2000) advocates cross-disciplinary education that emphasizes communication skills. She suggests that traditional disciplinary-specific programs which simply transmit information to students who accept it without question is insufficient for responding to contemporary policy issues. From her experiences, she concludes that, "One of my greatest challenges with undergraduate students is to move them from a position of passively accepting facts to a position of asking and answering questions" (41).

In agreement with McLellan's ideas, the Riparian Project challenged students to consider an issue from multiple perspectives and to apply diverse types of information to their analyses. The project's pedagogical goals centered on enabling students to make critical connections among various disciplines and applying their skills and knowledge to a management question that was based on a real scenario. The Riparian Project deemphasized regurgitating facts. As with real policy decisions, there was no absolute "right" answer, and the project allowed students to develop a large array of potential responses that reflected which questions they asked.

Earth Semester was always advertised as "hands on," "experiential," and "field-based" education. These attributes fit well with several of the methods that Astin (2001) identifies as being effective in developing talent among students. The Riparian Project encompassed the following of Astin's methods. 
- Being interdisciplinary—Biosphere 2 "faculty" included Ph.D. level professors, Masters level instructors, and Bachelors level teaching assistants from diverse disciplinary backgrounds in earth sciences, biological sciences, social sciences, and humanities.

- Having students take courses in common-all Earth Semester students simultaneously took three core courses: Ecological Systems, Earth Systems Science, and Human Role in Environmental Change.

- Encouraging collaborative learning (peer teaching)—Earth Semester students had majors ranging from art history to zoology and much of the curriculum focused on group work, so the students quickly recognized that teaching each other was an effective way to leverage time to complete necessary tasks.

- Providing opportunities for independent learning - much of the work necessary to complete the Riparian Project was completed outside formal class time. While they were given guidelines and had significant class time devoted to skill building, many aspects of the project were left to student discretion.

This project gave students experience in collecting data from various disciplinary perspectives and integrating that data into a policy recommendation that was presented both orally and in a written report. Although only anecdotal, feedback from alumni suggests that the project succeeded in teaching students to accept complexity, to identify useful questions, and to learn how to integrate relevant information.

\section{EARTH SEMESTER BACKGROUND}

In 1996 Columbia University took over operations at the Biosphere 2 Center in Oracle, Arizona, and established Earth Semester; a semester-long, immersive and integrated program. As in "Study Abroad" programs, students from universities all over the world came to Arizona to spend a semester learning to step beyond a disciplinary approach to problem solving. As Figure 1 illustrates, unlike traditional disciplinary programs where the emphasis is on delving deeply into a single subject area, Earth Semester's focus was on the intersections among disciplines. In 2003 Columbia University decided to eliminate all academic programs at Biosphere 2 and the final Earth Semester ended in December. 

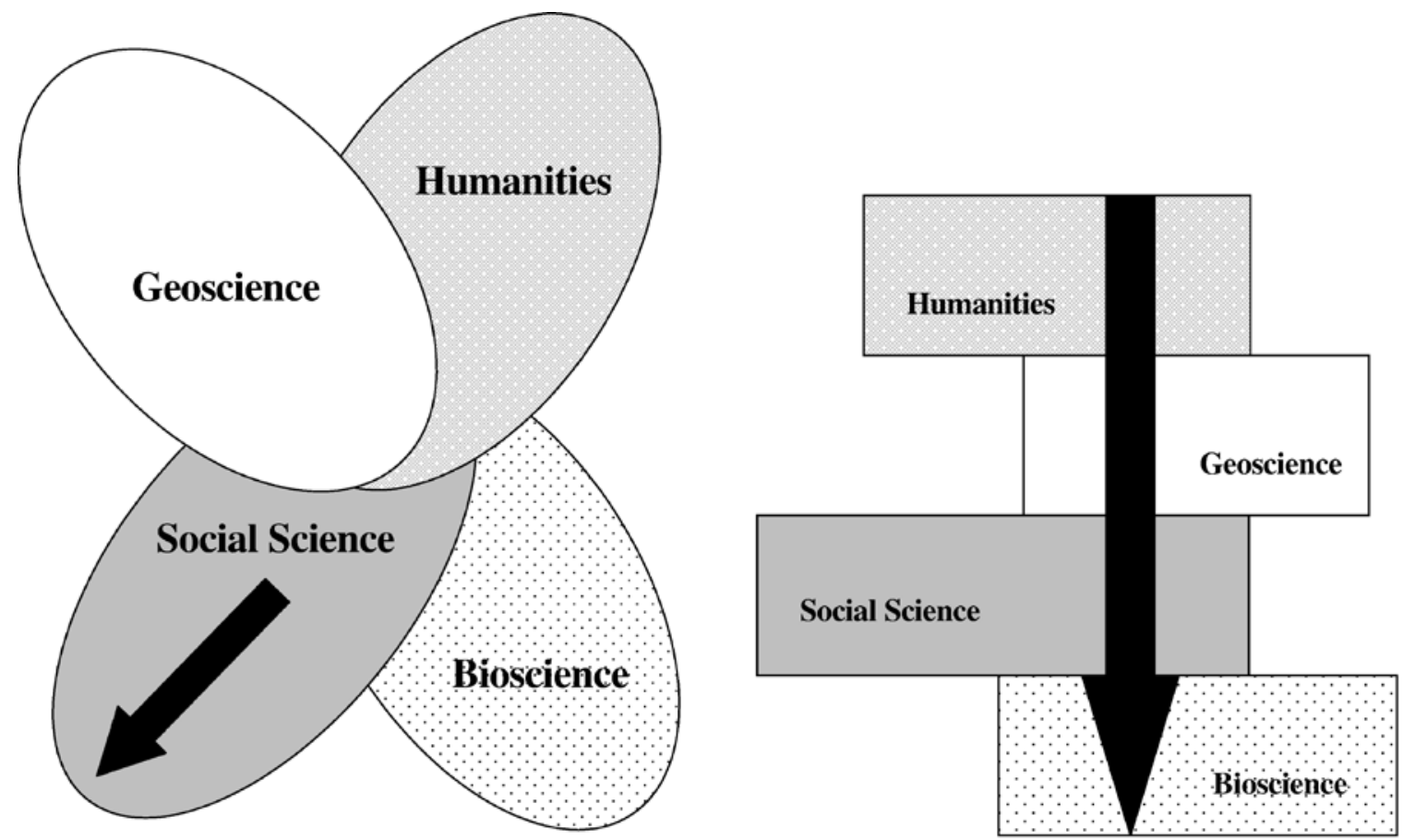

Fig. 1. The arrow shows of depth. On the left, a discipline-focused approach. On the right is the same image in side view, showing the Earth Semester interdisciplinary depth.

As Manning (1998) has noted, there is no formula for interdisciplinary curriculum development. The Earth Semester faculty consistently struggled with the issues Manning summarizes: breadth versus depth, disciplinary versus interdisciplinary, knowledge versus thinking, facts versus values, and balancing social sciences with life and physical sciences. The faculty refined the Riparian Project to focus on critical thinking as well as honing skills in teamwork and effective communication. The hope was that students would take these concepts back to their home universities and apply them to their future experiences.

A key goal was to blur the lines between courses (disciplines). Regardless of a student's major, the faculty hoped that students would connect the knowledge and skills they gained in one course to those in another-ideally taking these connections beyond what the faculty explicitly identified. While lectures and discussion sessions were listed as part of a particular course, the subject matter for all courses during the semester's first five weeks flowed toward the Riparian Project.

The nature of the program meant that there was not a typical day or week for students or faculty. But, as an example of discipline blending, Table 1 provides a class schedule for the required core courses for one week during the Riparian Project. 
Table 1

Class schedule for a student for one week of the Riparian Area Management Project

\begin{tabular}{|c|c|c|}
\hline Day & Morning & Afternoon \\
\hline Mon & Lecture (1 hr): Intro to Policy Process. & $\begin{array}{l}\text { Lectures ( } 1 \mathrm{hr} \text { ea): Intro to Hydrology; } \\
\text { Characteristics of Island Biogeography. }\end{array}$ \\
\hline Tue/Wed & $\begin{array}{l}\text { Small group discussion session on policy } \\
\text { processes and project connections. ( } 1 \mathrm{hr}) \text {. } \\
\text { Riparian Project team meeting to discuss } \\
\text { group dynamics. ( } 1 \mathrm{hr} \text { ). }\end{array}$ & $\begin{array}{l}\text { Gather field data with Riparian Project team } \\
\text { (4 hrs T or W). }\end{array}$ \\
\hline Thu & Independent research day, no classes. & \\
\hline Fri & $\begin{array}{l}\text { Classroom "lab" designed to have student } \\
\text { groups make a policy decision ( } 2 \text { hrs). }\end{array}$ & $\begin{array}{l}\text { Lectures (1 hr each): Ecophysiology of } \\
\text { Desert Plants; Water in the Southwest. }\end{array}$ \\
\hline
\end{tabular}

In addition to atypical schedules for their classroom and lab time, Earth Semester faculty also spent significantly more time coordinating than their counterparts in a traditional setting. Because all syllabi had to be synchronized and because all faculty participated at some level in the long field lab sessions, it was necessary for each instructor to have a rudimentary understanding of the concepts being taught in every course. Therefore, all faculty members met for approximately 20 hours at the beginning of each semester and for several hours each week during the semester.

\section{DEVELOPING THE PROJECT}

All full time faculty members worked collaboratively to develop the Riparian Project. The genesis was an idea to develop a curriculum whereby the three core courses would be taught to a central theme that emphasized a "real" decision-making issue. Of course, segments of the project were contrived to fit within an educational setting. As noted in the introductory materials distributed to students, the project was much like historical fiction-based in reality, but modified so that it could be applied within space, time, and student ability constraints.

In late 2000, Earth Semester student housing was located in a riparian area, but Columbia began constructing a new "student village" to provide housing and meeting space outside the riparian area. During a brainstorming session about the curriculum, the faculty decided that using the pending changes in the campus would provide an excellent scenario for teaching. It was believed that using a campus-focused issue would help students see the personal stake they have in integrating information to help lead to sound decisions. Therefore, the faculty settled on a project that asked students to conduct research relevant to the riparian area and to recommend to the Columbia Board of Trustees a preferred alternative for managing the area after the new student village was complete. This focus remained applicable through the Earth Semester's final session, because the riparian area was unchanged even after the student village opened.

Once the faculty had a general topic, the planning focus turned to outlining how the project would progress, what the final products would be, and how to develop individual course syllabi 
to flow around the new theme. The faculty discussed at length the pedagogy to be applied, and more by default than by any intentional decision-making process, the group came to consensus that the project's key lessons should include:

\author{
Gathering data, \\ Analyzing data, \\ Integrating data from disparate disciplines, \\ Applying data to a problem, \\ Group dynamics, and \\ Communication (speaking, writing, data presentation).
}

The faculty also decided to create a manual to help guide the students. After agreeing on the items to include, one faculty member took responsibility for compiling the initial draft. All faculty members had the opportunity to provide comments and suggest revisions to the draft and one faculty member integrated the comments to create the original manual used in Spring 2001. Based on student and faculty feedback, project logistics and the manual were significantly revised between Spring 2001 and Fall 2001, as the "Lessons Learned" section details. The changes proved successful and changes in subsequent semesters were less significant.

\title{
PROJECT DESCRIPTION
}

The project's frame was that each student assumed the role of a "consultant" whom the Columbia University Board of Trustees hired to conduct research and provide a recommendation for how to best manage the riparian area once the student village was complete. The student body was divided into six to eight groups (depending on the total number of students) so that each consulting team included six to 10 people. The faculty-written manual was the core document for the project and provided background information and specific descriptions of the tasks that had to be completed. The manual described the four approved alternatives and provided a five million-dollar budget for implementing the preferred alternative. Limiting the decision-making process to one of four options was designed to help students begin to focus immediately on asking pointed questions and to avoid overwhelming them by not providing any parameters. Faculty members encouraged the teams to think creatively about structuring a plan within one of the four approved options, but they could not create any new options.

The manual provided general information about riparian areas, appropriate methods for collecting data, survey data pertinent to the project's social aspects, guidelines for preparing the final presentation and report, as well as a grading rubric for the entire project. The manual, 
combined with 12 hours of field-based labs, provided the majority of the information needed for each group to prepare a rough draft of their report.[1]

A primary component of the project was a stakeholder assessment. The manual identified key stakeholder groups (students, Columbia University, tourists, researchers/faculty, ranchers, local conservation interests) and provided some information about these groups and their divergent views relevant to the decision. The campus was housed on a working ranch located next to state lands in an ecologically sensitive area. Biosphere 2 Center attracts almost 200,000 visitors per year and public education is part of the Center's mission. Additionally, there were full time researchers, as well as faculty, who conducted research on campus. Their final presentations typically reflected that the stakeholder assessment helped students recognize that competing interests, values, and levels of influence can greatly affect a decision-making process, and that they needed to explicitly address potential ramifications of favoring one stakeholder group over another.

Another crucial part of the project was for the consultant groups to gather pertinent data from physical, life, and social sciences. The students gathered physical data from the riparian area to be managed, which experienced high levels of human use, and from a second riparian area near the campus that is located on state land and is grazed but otherwise unused. This established a comparative component so that students could analyze the potential impacts that direct human use has on riparian areas. For each site, on each visit, students recorded metadata such as temperature, weather conditions, time, and group members participating. Then, at each site they established a transect with quadrats and gathered the following information relevant to each transect:

Aspect and slope,
Soil infiltration rates,
Plant cover,
Plant and animal diversity, and
Direct evidence of human impact.

As part of the overall assessment, the students also gathered data about economic and legal aspects related to each alternative. This was completed primarily via web-based searches. While they gathered data, students were asked to consider the data-gathering process itself and reflect on potential error sources.

Once the data were gathered each group analyzed the data relative to each of the four management alternatives, integrated the data into an informed decision and recommended a preferred alternative to the "Board of Trustees" (the faculty). Each group gave a 20-minute presentation on their work and submitted a robust written report on the project. 


\section{LESSONS LEARNED}

After several semesters and numerous completed project reports, the faculty learned numerous lessons. Most importantly, the faculty agreed that there was something right with the effort as the reviews were predominately positive even though there were always initial student complaints that the project was "impossible" and "too much work!" Consistent with Earth Semester's overall approach to education, the faculty modified the Riparian Project each semester to incorporate new ideas, many of them based on student feedback about the project.

Like most new endeavors, the first semester was the most difficult. Generating the initial outline for the project and the manual was extremely time intensive. A key lesson learned was that there needs to be one person who is a "pusher," someone who ensures that, during the development phase, drafts are compiled, reviewed and revised. As the project is being implemented, this person needs to ensure that pieces coming from the various disciplines are synchronized with the overall project goals and schedule.

One of the crucial lessons from the first semester was that the faculty drastically overestimated student ability to self-direct and to integrate information. In that initial semester, students were given the manual and largely left to their own devices to find the connections. It became abundantly clear that the students were not prepared for this and did not have the skills to make connections between what they were hearing in the classroom and what they were being asked to do in the Riparian Project. The only deadline was the final due date for the presentation and the report. The result was that several final reports included a chapter on the ecological data, a chapter on the earth science data, a chapter on the social data, and a recommendation based on students' personal beliefs with no support from the data! The groups also experienced a great deal of internal strife, and they were not able to apply information from readings and lectures about group dynamics and conflict resolution to their own situations. One reason for strife was that all group members received the same grade for the project and there was therefore initial tension related to perceived (often justified perceptions) "slackers" among the group.

The second semester the faculty added a level of instruction and guidance for helping students learn to integrate data into both their decision-making process and their final products. Revisions included reorganizing the manual and providing more explicit information about data analysis and integration. To provide more guidance, additional deadlines were added for students to submit drafts of various components of the project, including draft hydrological data, draft biologic data, and draft stakeholder assessments. Faculty provided extensive comments, but did not grade these drafts. This greatly improved data integration in the final presentations and reports. Additionally, the faculty designed several sessions to work with group dynamic issues. Unfortunately, several of these sessions were scheduled for September 11, 2001. Losing these sessions and the overall high stress levels generated from the events of that day, manifested in conflict within the groups.

In Spring 2002, the third semester for the Riparian Project, individual faculty members mentored student groups and successfully delivered information and guidance in the classroom 
concerning communication skills and issues relevant to group work. This approach was extremely effective in defusing potential crises within the "consulting" groups.

As with any realistic, management-based project, the faculty brooked student frustration with the fact that there is no "right" answer. Students in each semester have been uncomfortable with how "fuzzy" this kind of project can be. Faculty response has been first, to reassure students that their grades are not hinging on finding the "right" answer, but on identifying and applying information in justifiable, defensible ways; and second to reiterate that what they are experiencing is preparing them for the realities of environmental work.

Another observation has been that students have a tendency to introduce bias by adjusting data to account for perceived errors or to emphasize a desired outcome (e.g., moving a transect line because it doesn't have enough plants on it). In many cases this may be linked to the propensity for students to select their favorite management alternative and then try to make the data fit. Of course, they do this while at the same time criticizing examples they see in the "real world" where policy-makers ignore scientific (especially ecological) evidence when making a decision! Faculty would point this out to students and generate a discussion about proper data use and the implications for policy decisions.

From the faculty perspective, a lesson has been how difficult it is to find that fine balance between giving students personal (biased) ideas about the "best" way to interpret and integrate data and allowing them to learn on their own. Finally, the faculty recognized that it would be extremely valuable to study formally the impact that this project had on students' ability to think critically and solve complex problems. Unfortunately, resource constraints never permitted such a formal assessment of either the Riparian Project or Earth Semester as a whole. Student reviews, however, frequently included comments like, "life changing," "transformative," "eyeopening" and students often explicitly stated that they felt better prepared for their future academic and professional lives.

\section{APPLICABILITY TO OTHER PROGRAMS}

The Riparian Project was successful largely because the Earth Semester faculty were dedicated educators who believed in the power of immersion and interdisciplinary learning. For a project like this to succeed, coordination among faculty must be tight. Earth Semester faculty meetings prior to each semester focused on ensuring that the syllabi for core courses were synchronized and geared toward teaching the skills and concepts directly applicable to the Riparian Project. Each semester faculty adjusted syllabi to integrate more deeply and to incorporate lessons learned. There was a continuous learning process to identify links between and among the disciplines and to identify ways to help the students discover those links for themselves.

While Earth Semester was explicitly designed to foster these strong connections, the Riparian Project, with some modifications, is applicable to any program that wishes to bridge disciplines. For example, in a traditional program, the project could be the focal point for an upper-level environmental studies course and could encompass the entire semester. Any course that is 
team-taught could adopt the Riparian Project as a model and could select an issue relevant to the disciplinary expertise available and relevant to their campus.

Perhaps the biggest advantage Earth Semester has was the ability to create 4-6 hour fieldbased labs that all students attended. This can be accommodated in a traditional setting by ensuring that the equivalent of the Riparian Project builds on skills students should have acquired in previous courses. For example, if students are required to take an introductory environmental law course, then the skills learned in that course for identifying potential legal concerns can be utilized in the focal project but would not need to be included in the project's formal class time. Of course, this requires strong coordination among faculty to know what skills are taught in which courses. In this respect, programs in a more traditional setting have an advantage over Earth Semester. Because Earth Semester courses had no prerequisites, faculty could not assume that any of the students possessed any of the skills required to complete the Riparian Project. Hence, much of the class/lab time early in the semester focused on teaching these skills. Within a program with required courses, faculty could establish research teams that intentionally mix students who have expertise in the various skills (i.e., those who have completed various sets of course work). This would allow the team members to teach each other and complete data gathering and analysis tasks outside of class. Formal class time could then focus on the integrative issues as well as communication and group dynamics. With a dedicated faculty team and a willingness to adapt as issues arise, a modified Riparian Project could be applied almost anywhere, including the K-12 level.

\section{CONCLUSIONS}

The faculty always took pride in the fact that alumni report back that Earth Semester made a difference in their lives and in their approaches to education and careers. Faculty continue to hear from alumni who say that they now see limitations with "traditional" education. For example, one woman wrote about a year after attending Earth Semester, that she was frustrated because her economics professor (at her home institution) could not make connections among the economic principles she was teaching and other issues such as natural resource management or policy decisions. The student believed that her questions seeking connections were annoying the professor (likely so). Another example comes from an alumna who concluded that while the discipline-specific tasks were less challenging than courses at her home institution, her Earth Semester experience taught her how to ask better questions which led to more thoroughly appreciating the complexity within any issue. Based on responses like this, the faculty believe that the program succeeded in accomplishing McLellan's goal of getting students not simply to accept facts, but also to question, to think, and to seek not "right" answers, but perhaps more robust potential answers. 


\section{REFERENCES}

Astin, A. (2001). Fostering student engagement in learning: Lessons from recent research. Faculty Development, 15, 3.

Colodner, D., \& Cockerill, K. (2000). Abroad in Arizona: Interdisciplinary immersion education at the Biosphere 2 Center. Abstracts with Programs, 2000 Geological Society of America Annual Meeting, 32(7), A420.

Galea, C. (2001). Experiential simulations: Using webenhanced role-plays to teach applied business management. Journal of Information Technology and Management, 2(4), 473-489.

Manning, R. E. (1998). Integration in natural resources education: Designing a core curriculum. Society and Natural Resources, 11, 179-190.

McLellan, E. (2000). What Johnny really needs to know: A view from the Hill. Geotimes, 45(10), 12.

Meffe, G. K., \& Carroll, R. (Eds). (1997). Principles of Conservation Biology, 2nd edition. Sunderland, MA: Sinauer and Associates.

Rowe, J., \& Bjornerud, M. (1999). Volcanic petrographic textures in ceramic glazes. Abstracts with Programs, 1999

Geological Society of America Annual Meeting, 31(7), A82. Susskind, L. E., Jain, R. K., \& Martyniuk, A. O. (2001). Better environmental policy studies: How to design and conduct more effective analyses. Washington, DC: Island Press.

Whitman, J. (1996). An Environmental studies program: Linking the natural sciences, social sciences and humanities through an interdisciplinary watershed study course. Abstracts with Programs, 1996 Geological Society of America Annual Meeting, 28(7), A400. 